\title{
ESTUDO DE CASO DO LEAD TIME DE UM CENTRO DE PRODUÇÃO E DISTRIBUIÇÃO REVERSA DE PALETES DE MADEIRA NA REGIẪO DE BEBEDOURO ESTADO DE SÃO PAULO
}

\author{
LEAD TIME CASE STUDY OF A CENTER FOR PRODUCTION AND REVERSE \\ DISTRIBUTION OF WOODEN PALLETS IN THE BEBEDOURO REGION OF SÃO \\ PAULO \\ Cesar Augusto Eugênio ${ }^{\mathrm{I}}$ \\ Luiz Rodrigo Bonette ${ }^{I I}$
}

\begin{abstract}
RESUMO
O presente estudo tem como objetivo principal apresentar considerações sobre algumas atividades de produção e distribuição da logística reversa de paletes através do tempo de atividade (lead time). $\mathrm{O}$ estudo de caso único foi realizado com base em um Centro de Distribuição (CD) de uma empresa de processamento de alimentos no Brasil. A justificativa se baseia em duas necessidades emergentes, a primeira de oferecer maior competitividade para as organizações e adesão de estratégias corporativas sustentáveis dentro da cadeia de logística reversa de unitizadores, e na segunda necessidade é sobre a otimização de tempo com base em readequação das atividades de produção e distribuição reversa. Considera-se que o mapeamento do lead time dos processos reversos de distribuição e produção indicam que é uma ferramenta disponível às empresas que buscam ganhar diferencial e, no processo produtivo reverso de paletes, para expandir seu monitoramento em processos e tempos de produção e distribuição da matéria prima secundária e reprodução de novos paletes para revenda.
\end{abstract}

Palavras-chave: logística reversa; logística de distribuição; lead time, normatização de paletes.

\begin{abstract}
The present study has as main objective to present some considerations of production and distribution activities of the reverse logistics of pallets through time (lead time). The case study was conducted on the basis of a distribution center (DC) for a food processing company in Brazil. The justification is based on two emerging needs, the first to offer greater competitiveness for organizations and membership of corporate sustainable strategies within the reverse logistics of unitizers and the second need is on the optimization of time based on readjustment of production and distribution activities. It is considered that the mapping of the lead time of the reverse processes of distribution and production indicate that is a tool available to companies seeking win differential and reverse pallet production process to expand your monitoring in processes and production times and secondary raw materials distribution and reproduction of new pallets for resale.
\end{abstract}

Keywords: reverse logistics; distribution logistics; lead time, standardization of pallets.

\footnotetext{
I Faculdade de Tecnologia (Fatec) de Bebedouro - SP - Brasil. E-mail: cesar.aeugenio@ gmail.com

II Prof. Me. da Faculdade de Tecnologia (Fatec) de Bebedouro - SP - Brasil. E-mail: luiz.bonette@fatec.sp.gov.br
} 


\section{(11)}

Data de submissão do artigo: 13/07/2019.

Data de aprovação do artigo: 01/10/2019.

DOI:

\section{INTRODUÇÃO}

A maneira como os paletes são usados nos ambientes logísticos está em evolução constante. Enquanto a pouco anos atrás a forma de montar e unitizar as cargas se dava conforme a necessidade do cliente e não realizando a padronização conforme vemos cada vez mais em uso no cotidiano logístico. Leite (2003) descreve que o mercado está em constante expansão, com crescimentos na ordem de 8,6\% ao ano (superando, inclusive, o de caixas plásticas). $\mathrm{O}$ maior motivador dessa mudança na forma de consumo está relacionado à questão operacional.

Essa transformação no consumo de paletes acarretou a necessidade de criação de embalagens para transportar e comercializar os produtos, gerando um descarte muito grande de madeira no meio ambiente. Com intuito de reduzir impactos ambientais e custos, tem-se uma grande utilização de paletes, mais comuns nos padrões Palete Brasileiro Intercambiável ou convencional (LEITE, 2003).

O estudo analisa todo o processo de distribuição, até a coleta para reutilização e reuso na unidade produtora para envio ao mercado interno e externo, sobre os aspectos da logística direta e reversa.

A regulamentação técnica referente aos paletes tanto fabricação, quanto no seu manuseio tem como base de consulta as Normas Brasileiras Regulamentadoras: (ABNT NBR 8252, 2011; ABNT NBR 8334, 2011). A primeira diz respeito à padronização de altura, volume e densidade da madeira. A segunda normatiza a classificação da embalagem. A terceira padroniza a terminologia. Estes aspectos serão observados também no presente trabalho.

A questão de logística reversa aumenta o interesse pela crescente preocupação com o meio ambiente e acima disso, com a preocupação de atender aos desejos dos clientes e reduzir custos (LEITE, 2003). Já para Carneiro (2002) no processo da logística reversa, os produtos passam por uma etapa de reciclagem e voltam novamente à cadeia até ser finalmente descartado, percorrendo o "ciclo de vida do produto". Objetivo da pesquisa é mapear e expor um case focado no lead time dos processos de distribuição de paletes reversos com base no encerramento centralizado da viagem, canhotos e vale-paletes a fim de reduzir o tempo no processo de distribuição reversa. O tempo das atividades reversas pode ser diminuído sem que afete o fluxo do processo reverso e do seu canal reverso sem que impacte na qualidade das entregas.

O trabalho está estruturado nas seguintes seções: o texto introdutório ao contexto da pesquisa e suas metas de investigação, o desenvolvimento das argumentações de autores com a temática de logística reversa; logística de distribuição; lead time, normatização de paletes, as seções finais são o resultado do processo reverso de distribuição mapeado e suas considerações a aspectos que podem otimizar o tempo destas atividades de produção e distribuição. 


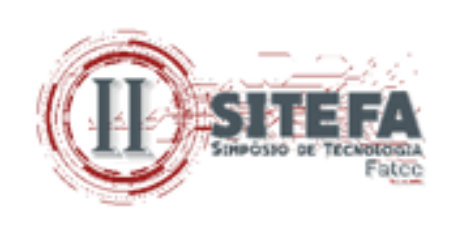

\section{LOGÍSTICA REVERSA}

A área da logística empresarial que planeja, opera e controla o fluxo e as informações logísticas correspondentes, do retorno dos bens de pós-venda e de pós-consumo ao ciclo de negócios ou ao ciclo produtivo, por meio dos canais de distribuição reversos, agregando-lhes valor de diversas naturezas: econômico, ecológico, legal, logístico, de imagem corporativa, entre outras (LEITE, 2003).

Carneiro (2002) explica que a logística reversa pode ser entendida como um processo complementar à logística tradicional, pois enquanto a última tem o papel de levar produtos de sua origem dos fornecedores até os clientes intermediários ou finais, a logística reversa deve completar o ciclo, trazendo de volta os produtos já utilizados dos diferentes pontos de consumo a sua origem.

Rogers e Tibben-Lembke (2001) explicam que custos de transporte não devem ser os únicos a serem considerados em decisões sobre embalagens retornáveis, já que estas também afetarão custos de manuseio e rastreamento de embarques.

Lacerda (2002) indica que o uso da logística reversa é um canal de utilização e implementação desta ferramenta. Pois ela se estabelece em 3 pilares: Questões ambientais, Concorrência e Redução de Custo.

Margeando na legislação ambiental que converge no caminho de deixar estabelecido que a empresa seja responsável por todo ciclo de vida do seu produto. Porém no que condiz no ambiente logístico e no segmento de armazenagem frigorificada, o palete é considerado um item pois é expedido e referenciado com Nota Fiscal e é controlado fiscalmente e deve ser mantido conforme normas e acordos firmados de proteção ambiental e florestal. Abordando o âmbito da concorrência, o varejo acredita que há uma valorização e preferência entres os clientes e usuários por empresas que atuam com essa ferramenta (NOVAES, 2016).

Carneiro (2002) afirma que são estruturados os processos e recursos na logística, com isso a tratativa direta a produtos danificados e quaisquer que possam retornam via devolução.

Já o que aponta sobre a redução de custo, as empresas estão contabilizando grandes ganhos de capital realizando a prática reversa. Pois a utilização de embalagens retornáveis e reaproveitadas dão essa possibilidade e trazem oportunidade para a criação de novas ações (GUARNIERI, 2011).

O processo de logística reversa resulta na criação e manipulação de materiais que serão reaproveitados que irão retornar aos processos de suprimento, produção e distribuição essa afirmação pode ser comprovada com os paletes. Pois o mesmo item que está no cliente final, futuramente está de volta a Unidade Produtora e será utilizado para ser parte integrante de toda a cadeia do processo produtivo (LIMA, 1998).

Adlmaier (2007) e Medeiros e Ronsani (2017) indicam que a logística reversa é canal inverso do produtor, levando em conta tudo que pertence a cadeia logística e produtiva que o bem está empregado. Com base em uma perspectiva gerencial o embasamento deste processo pode ser facilmente gerido por um Reverse Logistics Management (RLM).

A logística reversa é compreendida como a área da logística empresarial que planeja, opera e controla o fluxo de matérias e as informações logísticas com o ponto focal no retorno dos bens pós-venda e pós-consumo, atuando por meio dos canais de distribuição reversos e agregando-lhes valor de diversas naturezas, entre os quais se destacam: econômica, ecológica, legal, logística, de imagem corporativa entre outros.

O objetivo se dá por meio de fluxos reversos, tornar possível o retorno dos bens ou de seus materiais constituintes ao ciclo produtivo ou de negócios, usando de meios que vão 


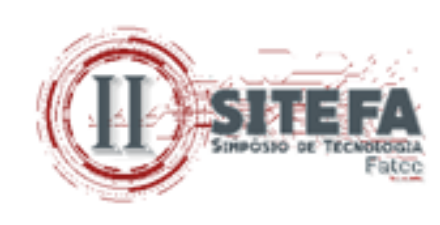

desde a operacionalização do fluxo, da coleta dos bens, por meio de processamento logístico, separação, seleção e até mesmo reintegração ao ciclo.

A crescente associação da logística reversa com recalls faz com o cliente final realize o descarte de forma correta e assim respeitando a leis e normas ambientais.

Leite (2003) a velocidade de descarte e reutilização correta não é proporcional ao volume de produção onde assim a atuação da logística reversa deve possuir a missão de conciliar o desejo e necessidades do consumidor, com o menor custo possível em prazo adequado.

Carneiro (2002), a logística reversa abrange os processos nos quais produtos e embalagens retornam do local de consumo para o local de origem. Os produtos podem conter defeitos, exigindo substituições ou manutenções.

\subsection{Logística de Distribuição}

A cadeia de distribuição clássica é formada com um único nível, que se resume no varejista, com os parâmetros entre o ponto de origem e final. Deve ser traçado o nível de atuação que atuara no projeto mercadológico (LEITE, 2003).

Novaes (2016) a distribuição tem uma meta central que consiste em levar os produtos corretos, para os locais e momentos corretos com nível de serviço desejado. Em diversos processos surge um antagonismo de manter o nível de serviço devido que diversas melhorias no sistema logístico geral acarretam aumento de custos com transporte, armazenagem e estoque.

Levando a constituir um desafio de garantir um nível de serviço elevado e ter como foco, ao mesmo tempo, a redução de custos atuante em todo o processo. Com a oferta de melhores níveis de serviços implica em maiores custos com armazenagem, transportes e estoques (NOVAES, 2016).

Entretanto, esta questão está ligada à ideia de valor agregado, ou seja, agregar valor através de serviços diferenciados (BOWERSOX; CLOSS, 2001). A oferta de diferentes níveis de serviços na logística de distribuição, envolvendo disponibilidade, frequência e confiabilidade de entrega está se tornando um diferencial competitivo. Os vários níveis de serviços oferecidos aos clientes são uma forma de diferenciar produtos, conquistar novos mercados ou ampliar a participação em clientes já tradicionais.

Leite (2003) descreve o cliente como um todo no mundo econômico está a cada dia dando mais importância a aspectos do equilíbrio ecológico. Assim dando mais visibilidade aos canais com inclusão de preservação e conduta que atende a preservação ecológica.

$\mathrm{O}$ aumento veloz do descarte dos produtos após o primeiro uso, motivados pelo aumento do descarte dos produtos em geral, não encontrando canais de distribuição reversos de pós-consumo devidamente ativos e organizados, causa a disparidade entre as quantidades descartadas e as reaproveitadas, gerando um grandioso volume de produtos descartáveis (LACERDA, 2002).

Carneiro (2002), no centro da logística reversa encontram-se os processos de recall e manutenção, trocas e devoluções e atividades promocionais geralmente iniciadas pelo departamento comercial. Com o auxílio dos meios de comunicação, a prática e os canais de comunicação estão cada vez mais acessíveis ao cliente final. 


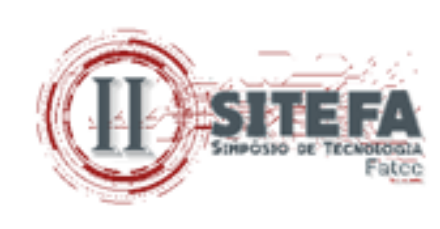

\subsection{Lead Time}

Lead time pode ser conhecido como tempo de aprovisionamento. Consiste em período entre o início de uma atividade, produtiva ou não, e o seu término.

A definição mais convencional para lead time em Supply Chain Management (SCM) é o tempo entre o momento do pedido colocado pelo cliente até a entrega do que foi solicitado.

Em resultado da definição mais genérica, lead time é, muitas vezes, confundido ou tem o mesmo significado de ciclo, tack time e deadline, entre outros (LAMBERT, 1998).

O lead time é um dos conceitos mais significativos da logística. Deve considerar todas as atividades, pois está associado ao custo da operação (NOVAES, 2016).

Para Novaes (2016) estão atrelados ao lead time:

- $\quad$ Estoque de segurança

- $\quad$ Lote econômico de compras

- $\quad$ Processos produtivos

Esse conceito é caracterizado para manter os níveis de recursos suficientes para evitar falta de estoque diante da demanda criada e na qual será atendida (DAHER; SILVA; FONSECA, 2006).

O lead time após introduzido tem o objetivo de sempre ser reduzido. Casos práticos podem ser observados na área de Compras e Produção. Ficando firmado e claro que vários fatores determinam o sucesso da logística.

Leite (2003) por outro ponto descreve que o focal do lead time é ter o desafio para evitar e insatisfação do cliente e manter o nível de serviço, resumindo que ele não pode ser maior do que o recebedor do pedido está disposto a aguardar.

\subsection{Normatização de Paletes}

O palete surgiu em meados de 1925, nos Estados Unidos e Norte da Europa, junto com o surgimento das primeiras empilhadeiras de que se tem registro. Seu uso sempre esteve ligado a atividades comerciais. Foi aplicado primeiramente nos transportes marítimos, para agilizar as operações de estiva (GUARNIERI, 2011). Os parâmetros e definições para sistemas estão nas normas da ABNT para armazenagem, sendo que no Brasil foi trazido pelas indústrias automobilísticas e supermercados, no final da década de 60 e início da década de 70, porém foi só nos anos 80 que o palete teve seu uso concretizado no Brasil, com o estabelecimento das (ABNT-NBR 8252, 1983).

Durante anos e dialogando com empresas de armazenagem e produtoras de paletes, a ABNT elaborou a norma numerada como NBR 15.524-2, publicada em outubro de 2008 e que tem sido a especificação básica para armazenagem de forma geral (CARNEIRO, 2002).

As normas da ABNT para armazenagem oferecem orientações de projeto, cálculo, montagem e uso das estruturas porta paletes, sendo assim, ela esclarece sobre carregamento de cargas, o modo de operação do sistema e a sua conservação.

Leite (2003) explica em relação à aplicabilidade das normas da ABNT para armazenagem acredita que ela acaba se impondo mesmo não sendo obrigatório seu uso, visto que na ocorrência de acidentes quem não a seguir poderá responder judicialmente. 


\section{(110)}

\section{PROCEDIMENTOS METODOLÓGICOS: coleta de Informações em um Ambiente Real de Trabalho}

Foi observado dentro do processo metodológico no estudo de caso único, em uma multinacional de processamento de alimentos (cortes de frango, linguiça, bacon, hambúrguer, presunto, mortadela e refeições prontas) instalada em território nacional com uma estrutura de 9 parques industriais e mais de 14.000 funcionários. Já a filial na empresa especializada em distribuição deste grupo especificamente tem em sua atividade principal econômica a coleta para reutilização e reuso de paletes na unidade produtora para envio ao mercado interno e externo, sobre os aspectos da logística direta e reversa com 38 funcionários e capacidade 4000 unidades mensais na produção de paletes reutilizáveis e 6000 paletes reversos em distribuição dos mesmos para outras empresas do grupo e também clientes que consomem este tipo de unitizador do mesmo segmento.

A pesquisa é de natureza da pesquisa aplicada, com objetivo da pesquisa descritiva, de abordagem da pesquisa qualitativa, acerca dos protocolos de estudo de caso único. A técnica de coleta de dados foi pesquisa documental através de relatórios ou outros documentos no aspecto temporal longitudinal do ano de 2018.

\section{RESULTADOS E DISCUSSÃO: das atividades desenvolvidas}

Existem períodos de controle e movimentação de paletes tem a principal finalidade de garantir a gestão e reutilização das embalagens. Assim após a emissão dos vales paletes eles seguem ao destino da entrega onde será assinado e acompanhará a Nota Fiscal (NF) da mercadoria que nele se consiste. A partir da referida emissão, o saldo contábil da embalagem é baixado e assim eles são deslocados via sistema para um local virtual onde aguarda o recolhimento para que o vale seja integrado fiscalmente.

A recolha é realizada por um veículo denominado "Papa Palete" onde se tem por finalidade a devolução de paletes pendentes em clientes e pontos de entrega. A partir da chegada do veículo, é realizado o acerto manual de estoque. Com isso a rastreabilidade e tratativas que serão dadas internamente as embalagens dão início a partir desse processo. Podendo ocorrer a devolução nas seguintes premissas:

- Vale Palete assinado e carimbado: Acontece quando o cliente retém os paletes. Obrigatoriamente precisa assinar ou carimbar o Vale Palete como comprovante de que irá devolver os paletes quando o for agendada uma coleta pela Central corporativa. Nesses casos, os vales devem ser enviados, via malote diariamente para a Central Corporativa.

- Vale Palete sem assinatura (transportador não devolve os paletes): Quando o transportador devolve o vale palete sem assinatura e não faz a devolução dos paletes, a quantidade descrita no vale deve ser transferida do cliente para o transportador, pois é responsabilidade do transportador que os paletes sejam devolvidos fisicamente ou via vale palete assinado.

- $\quad$ Os Vale Paletes que estiverem assinados / carimbados por outra unidade de origem deverá ser tratada como paletes devolvidos, e deverão ter a quantidade informada no fechamento da viagem. 
Figura 01 - Análise do lead time sequenciado pela empresa estudada em suas práticas

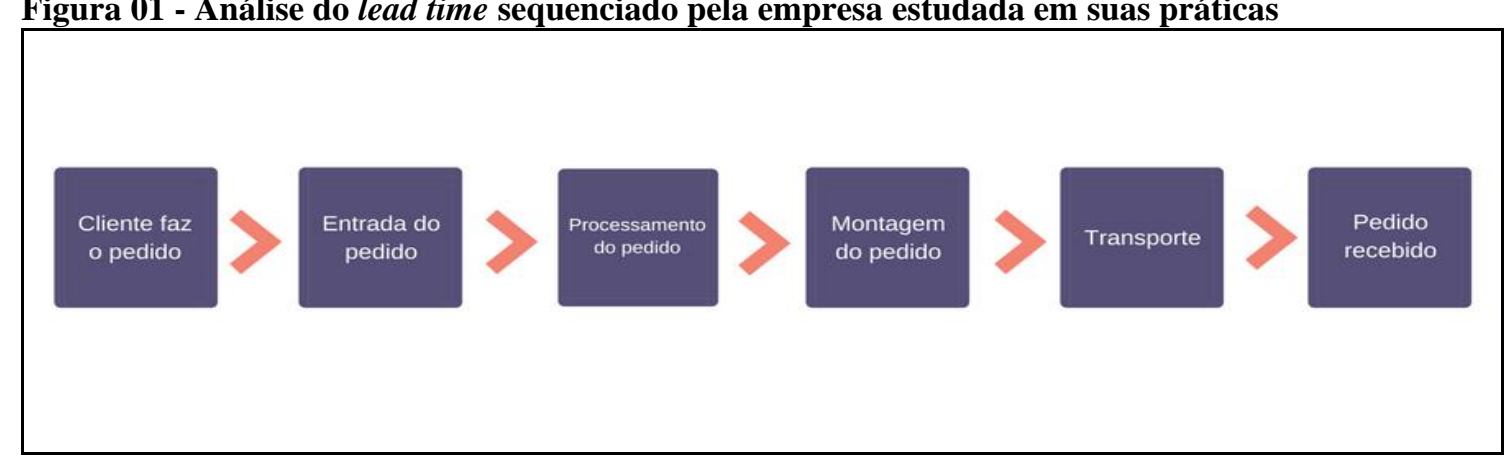

Fonte: os autores (2019)

\subsection{Resultados Obtidos}

Existem dois tipos de ações que são aplicadas no controle e movimentação dos paletes para cumprimento de sua distribuição reversa aos clientes próprios e de terceiros dentro do processamento de alimentos, como é observado:

1. Ação: bloqueio do faturamento sem emissão de vale-palete - solução em produção.

2. Ação: centralizar retorno de documentos (canhotos e vale-paletes) da venda direta.

Figura 2 - Cenário Anterior sem a aplicação do Pré-Projeto para 100 dias para retorno do palete através de seu caminho crítico

\begin{tabular}{|l|l|l|}
\hline $\mathbf{5 3}$ dias & $\mathbf{3 3}$ dias & $\begin{array}{l}\text { Entrega dos } \\
\text { documentos pelo } \\
\text { transportador }\end{array}$ \\
\hline & $\begin{array}{l}\text { Encerramento } \\
\text { da viagem na } \\
\text { filial de origem }\end{array}$ & $\begin{array}{l}\text { Chegada do } \\
\text { documento } \\
\text { na Central } \\
\text { de Paletes }\end{array}$ \\
\hline
\end{tabular}

Fonte: os autores (2019)

Neste caso é observado no fluxo que:

- $\quad$ O tempo total que compreende entre a expedição do palete na fábrica até o retorno da documentação pelo transportador após efetuar a entrega era de 100 dias.

- Mais da metade deste período era consumido entre a entrega do pedido e a estadia dos paletes nos clientes.

- Como não possuía uma padronização de processos no fechamento das viagens, a comunicação e coleta ficavam limitadas ao contato do cliente solicitando para que liberasse espaço no estabelecimento comercial. 


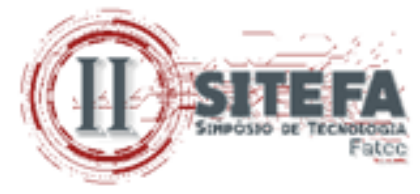

Figura 3 - Cenário atual após a implantação do projeto

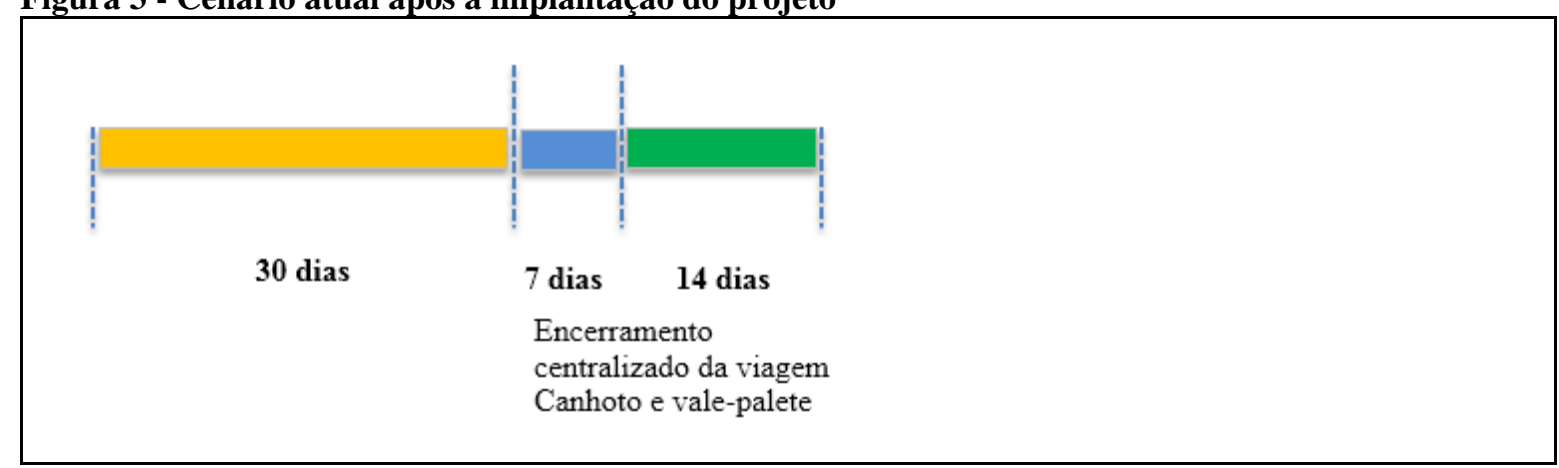

Fonte: os autores (2019)

Neste caso é observado no fluxo que:

- $\quad$ O Lead Time foi reduzido em 51 dias, onde pode observar a melhoria no desemprenho de todo o processo.

- Como a utilização do vale-palete, a redução do tempo de ciclo foi de aproximadamente $50 \%$, em um ciclo que é compreendido entre a saída na Fábrica até o retorno no $\mathrm{CD}$ pós realização da entrega.

Figura 4 - Giro de paletes

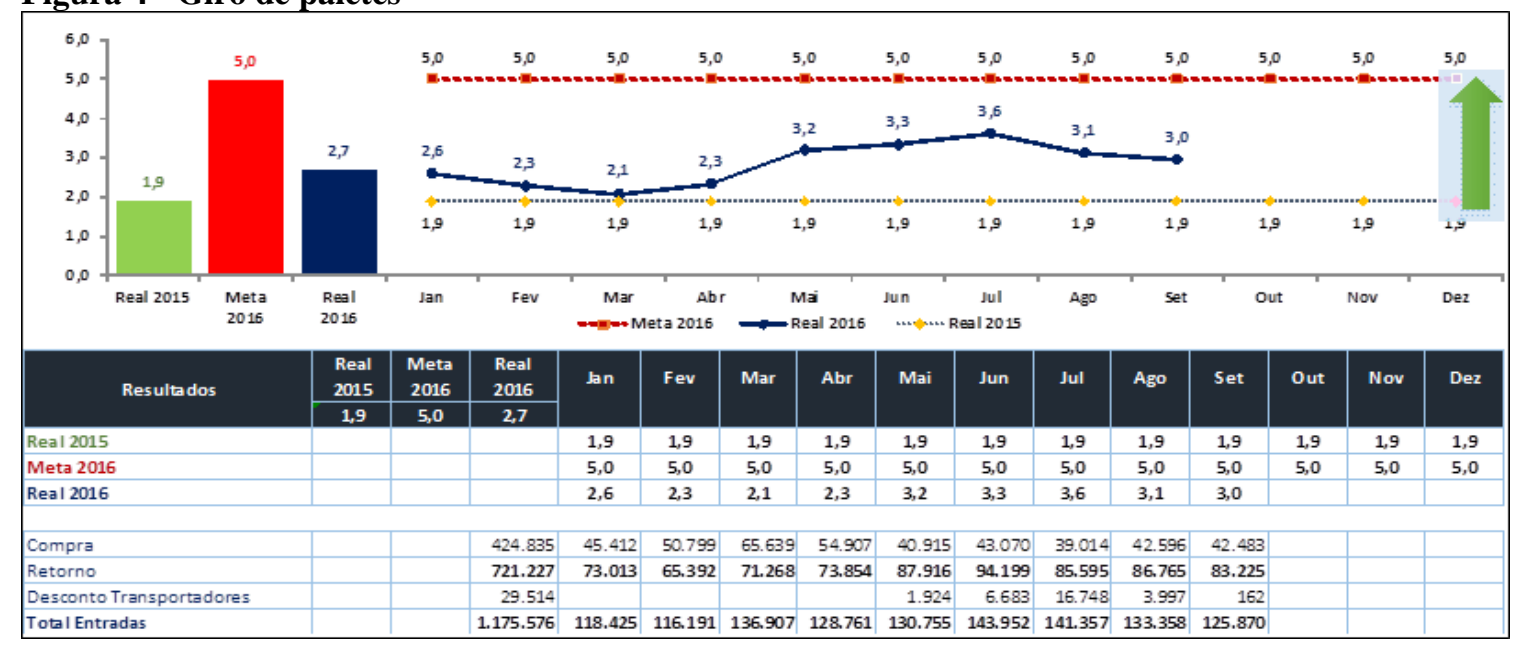

Fonte: os autores (2019)

Neste caso é observado no fluxo que:

- $\quad$ Foi levado em conta um levantamento do ano de 2016, onde trata-se do primeiro ano com o processo iniciado em toda a operação. O cenário era conforme demonstrado na

- $\quad$ Figura 2. Com tendência de crescimento mensal comparado ao mesmo período do ano anterior

- $\quad$ O ano fechado (Jan - Dez) de 2015 teve a média de 1,9 vezes / paletes ao mês, entretanto de Jan a Set / 2016 os números estão 58\% maiores. Podemos tomar a seguinte conclusão de que a cada 1.000 paletes expedidos em entregas, 580 retornarão ao CD dentro do lead time já exposto. 


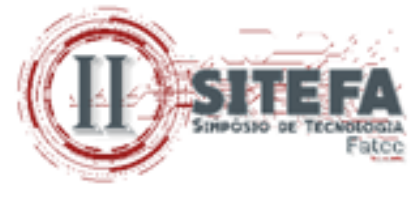

\section{CONSIDERAÇÕES FINAIS}

Levando em consideração esses aspectos e dado referido como o exposto, a compra de paletes sofreu uma queda considerável e o giro está em constante alta. O tempo do retorno da embalagem para o local de onde foi expedida obteve uma redução de aproximadamente $50 \%$. A redução do lead-time causou impactos positivos em diversos setores. Pois o cliente se sente mais bem atendido, pois vosso estoque de paletes está em constante giro e com um nível de serviço padronizado. Um departamento foi criado especificamente para as tratativas com paletes. A tendência dos números referentes ao primeiro ano de implantação do projeto nos demonstra que pontos de melhoria foram instituídos, levando a crer no sucesso do uso em questão de todo processo. Sendo assim um cenário que é visível a redução de perdas, pois sem o projeto esses mesmos 580 paletes não teriam coleta e rastreabilidade. Sendo necessário a compra para reposição fabril e logística.

\section{REFERÊNCIAS}

ADLMAIER, D.; SELLITTO, M. A. Embalagens retornáveis para transporte de bens manufaturados: um estudo de caso em logística reversa. Production, v. 17, n. 2, p. 395-406, 2007.

ASSOCIAÇÃO BRASILEIRA DE NORMAS TÉCNICAS (ABNT). NBR 8252: paletes: dimensões básicas. 2011.

NBR 8334: paletes: classificação. 2011.

NBR 8252: paletes: dimensões básicas - padronização. 1983

BOWERSOX, D. J.; CLOSS, D. J. Logística empresarial: o processo de integração da cadeia de suprimentos. São Paulo: Atlas, 2001.

CARNEIRO, P. S. M. Logística reversa. Revista ESPM, São Paulo, v. 9, n. 3, p. 46-54, maio/jun. 2002.

DAHER, C. E.; SILVA, E. P. S.; FONSECA, A. P. Logística reversa: oportunidade para Redução de Custos através do Gerenciamento da Cadeia Integrada de Valor. BBR - Brazilian Business Review [en linea]. 2006.

GUARNIERI, P. Logística Reversa: Em busca do equilíbrio econômico e ambiental. 1. ed. Recife: Clube dos Autores, 2011.

LACERDA, L. Logística reversa: uma visão sobre os conceitos básicos e as práticas operacionais. Rio de Janeiro: COPPEAD/ UFRJ, 2002

LEITE, P. R. Logística reversa: meio ambiente e competividade. São Paulo: Prentice Hall, 2003. 


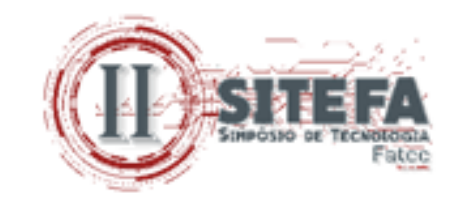

LIMA, M. P. Custos logísticos - uma visão gerencial, Rio de Janeiro: Centro de Estudos em Logística da Universidade Federal do Rio de Janeiro. 1998. Disponível em:

http://www.cel.coppead.ufrj.br. Acesso em: 10 jul. 2018

LAMBERT, D. M. Administração estratégica da logística. São Paulo: Vantine Consultoria, 1998.

MEDEIROS, J. de; RONSANI, C. M. S. Proposta para implantação de melhoria no processo de logística reversa de embalagens: estudo de caso em uma distribuidora de alimentos em Içara-Santa Catarina. In: Congresso Sul Catarinense de Administração e Comércio Exterior, 2017.

NOVAES, A. Logística e gerenciamento da cadeia de distribuição. Elsevier Brasil, 2016.

ROGERS, D.; TIBBEN-LEMBKE, R. An examination of reverse logistics practices. Journal of Business Logistics, v. 22, n. 2, p. 129-148, 2001. 